\title{
Contactless Vibrational Analysis of Transparent Hydrogel Structures Using Laser-Doppler Vibrometry
}

\author{
S. Schwarz ${ }^{1,2,3}$ (D) B. Hartmann ${ }^{1,3}$ (D) - J. Sauer ${ }^{4} \cdot$ R. Burgkart ${ }^{5} \cdot$ S. Sudhop ${ }^{1,3}$ (D) D.J. Rixen ${ }^{2}$ (D) \\ H. Clausen-Schaumann ${ }^{1,3}$ (B)
}

Received: 14 January 2020 / Accepted: 22 June 2020 / Published online: 13 July 2020

(C) The Author(s) 2020

\begin{abstract}
Background Investigating the mechanical properties of biological and biocompatible hydrogels is important in tissue engineering and biofabrication. Atomic force microscopy (AFM) and compression testing are routinely used to determine mechanical properties of tissue and tissue constructs. However, these techniques are slow and require mechanical contact with the sample, rendering in situ measurements difficult.

Objective We therefore aim at a fast and contactless method for determining the mechanical properties of biological hydrogels and investigate if an optical method, like Laser-Doppler vibrometry (LDV), can accomplish this task.

Methods LDV is a fast contactless method for mechanical analysis. Nonetheless, LDV setups operating in the visible range of the optical spectrum are difficult to use for transparent materials, such as biological hydrogels, because LDV relies on reflected or back-scattered light from the sample. We therefore use a near-infrared (NIR) scanning LDV to determine the vibration spectra of cylindrical gelatin discs of different gelatin concentration and compare the results to AFM data and unconfined compression testing.

Results We show that the gelatin test structures can be analyzed, using a NIR LDV, and the Young's moduli can be deduced from the resonance frequencies of the first normal $(0,1)$ mode of these structures. As expected, the frequency of this mode increases with the square root of the Young's modulus and the damping constant increases exponentially with gelatin concentration, which underpins the validity of our approach.

Conclusions Our results demonstrate that NIR wavelengths are suitable for a fast, contactless vibrational analysis of transparent hydrogel structures.
\end{abstract}

Keywords LDV $\cdot$ Mechanical properties $\cdot$ Biomaterials $\cdot$ Atomic force microscopy $(\mathrm{AFM}) \cdot$ Compression testing

Electronic supplementary material The online version of this article (https://doi.org/10.1007/s11340-020-00626-0) contains supplementary material, which is available to authorized users.

H. Clausen-Schaumann

hauke.clausen-schaumann@hm.edu

1 Center for Applied Tissue Engineering and Regenerative Medicine, Munich University of Applied Sciences, Lothstr. 34, 80335 Munich, Germany

2 Department of Mechanical Engineering, Technical University Munich, 85748 Garching, Germany

3 Center for NanoScience, Ludwig-Maximilians-Universität München, 80799 Munich, Germany

4 Polytec GmbH, 76337 Waldbronn, Germany

5 Klinik und Poliklinik für Orthopädie und Sportorthopädie, Technical University Munich, 81675 Munich, Germany

\section{Introduction}

Transparent elastic gels, such as biological and biocompatible hydrogels have a wide range of applications, from food technology [1] to cell biology [2] and biomedical engineering [3-5]. With recent advances in 3D-bioprinting technology and tissue engineering, mechanical properties of tissueengineered structures, as well as the material properties of the hydrogels themselves have become increasingly important [6], because there is growing evidence that cell fate and behavior are tightly controlled by the mechanical properties of the cellular microenvironment [7]. Cells sense the mechanical properties of their surroundings and receive mechanical stimuli from neighboring cells and from the extracellular matrix (ECM) [8-11]. Cell migration follows elasticity gradients [12-15], and cancer spreading [16] and metastases formation 
[17] as well as many other cellular processes, such as neuron growth or vascular tube formation by endothelial cells, can be stimulated and guided by ECM elasticity [18-21]. In order to design and construct functional tissue substitutes, knowledge and control of the elastic parameters of these hydrogels are therefore essential, and methods to characterize the mechanical properties of tissue-engineered structures with high spatial resolution are a prerequisite for this task. Furthermore, for direct fabrication of living, cell-laden structures, with 3Dprinting technologies, such as extrusion-based 3D-printing, the printed hydrogels have to be sufficiently stiff to sustain 3D structures and, at the same time, their viscosity during extrusion has to be low enough to keep shear forces on cells at a minimum to guarantee cell survival and viability [22]. Therefore, the hydrogels used for such applications have to undergo a rapid transition from low viscosity during the printing process (e.g. extrusion), to sufficiently high stiffness to form mechanically stable structures. To initiate and control this transition, temperature gradients, chemical or photochemical crosslinking or shear thinning are used $[3,5,23,24]$, and technologies which allow to monitor this transition can help to optimize printing parameters and are required for quality control $[25,26]$. Currently, indentation type atomic force microscopy (IT-AFM) is used as a standard method for spatially resolved characterization of the biomechanical properties of biological samples, such as cells, ECM, hydrogels and tissue sections with high spatial resolution $[8,21,27-30]$. However, IT-AFM is comparatively slow, it relies on mechanical contact between an indenter (typically a pyramidal tip) and the biological sample and is not readily integrated into biofabrication or other fabrication processes.

Laser-Doppler vibrometry (LDV) is widely used to investigate mechanical vibrations in structural analysis [31, 32], where it provides detailed insights into the behavior of engineered and natural structures subjected to dynamic forces, and provides access to material properties like elasticity and viscosity [33-39]. LDV is a fast contactless optical technology, which can acquire data from a distance at high temporal and spatial resolution and can readily be integrated into fabrication processes. A scanning setup allows for twodimensional measurements, providing access to the shape of the vibrational modes $[36,40]$. Nevertheless, because LDV relies on the optical Doppler effect, it requires that a sufficient amount of light is reflected or scattered back from the investigated object. For this reason, structures made of transparent, low refractive index materials, such as biological or biocompatible hydrogels, have been difficult to investigate by LDV. In previous studies, reflective markers, i.e. reflective particles or metal foils [41-43], were embedded in or placed on top of these materials to enhance the intensity of the reflected signal. However, for many applications, such as biofabrication or food technology, placing particles in or on top of the hydrogels is not feasible. Furthermore, the additional mass of these reflective markers can falsify the results [44, 45], and fine-meshed 2D-scanning of a vibrating surface is impossible if a discrete number of markers is used.

In the present study, we have therefore investigated whether the capabilities of LDV, which work well for reflective materials, can be extended to transparent materials, like hydrogels without using additional reflective markers. We have established a procedure, which allows distinguishing the elasticities of transparent hydrogels, using a near-infrared (NIR) scanning LDV. As test samples, we used $3 \mathrm{~mm}$ thick gelatin hydrogel discs with a diameter of $9.7 \mathrm{~mm}$. Samples of different gelatin concentrations were attached to the rim of a cylindrical sample holder and dynamically excited with a piezo actuator. To validate and quantify our results, we have compared the LDV data to the elastic parameters of the same hydrogels determined by IT-AFM and unconfined compression testing, which are two well-established methods for the characterization of the elastic parameters of biological samples $[8,21,46-51]$.

\section{Experimental Procedure}

\section{Optical Transmission Measurement}

The measurement of the optical transmission was done using a high-sensitivity thermophile sensor (PS10, Coherent Inc., Santa Clara, CA, USA). A $0.20 \mathrm{~g} / \mathrm{ml}$ gelatin hydrogel was directly cast into a sample holder, as described in section 2.4 and positioned over the sensor's opening. The LDV was positioned perpendicular to the sample surface as shown in Fig. 3 and the IR laser was turned on. At least a hundred data points were recorded from in total 12 different samples of varying thickness. Using the mean value for each sample, the absorption coefficient $\alpha$ for each of the $0.20 \mathrm{~g} / \mathrm{ml}$ gelatin samples was derived by fitting Lambert-Beer's law (Eq. 1) to the data:

$I=I_{0} e^{-\alpha d}$

where, $I$ is the intensity measured after passing the sample, $I_{0}$ the intensity without a sample (here $8.92 \mathrm{~mW}$ ), and $d$ is the thickness of the sample.

\section{Production of Sample Holder}

The custom made sample holder structures were made with a fused deposition modeling 3D-printer (Ultimaker 2+, Ultimaker, Geldermalsen, Netherlands) using a polylactide filament with a diameter of $2.85 \mathrm{~mm}$. CAD files of the sample holder were sliced for the 3D-printer with a layer height of $0.1 \mathrm{~mm}$ and a $0.4 \mathrm{~mm}$ nozzle diameter, using the Cura slicing software (Ultimaker, Geldermalsen, Netherlands). $100 \%$ infill was chosen to obtain solid structures and thereby minimize 
undesired resonances and dynamics in the low-frequency range, as much as possible.

\section{Hydrogel Preparation}

Gelatin hydrogels with different gelatin concentrations were made by mixing deionized water and crystallized gelatin powder (4308.1, Carl Roth GmbH \& Co. KG, Karlsruhe, Germany). To dissolve the gelatin, the mixture was placed on a heated magnetic stirrer at $55^{\circ} \mathrm{C}$. After $8 \mathrm{~min}$, the gelatin was completely dissolved and a clear, honey-like solution was obtained. To prevent evaporation during sample preparation and storage, the beakers were sealed with Parafilm (IDL GmbH \& Co. KG, Nidderau, Germany). The solution was then stored at $37{ }^{\circ} \mathrm{C}$ until needed for sample preparation, as described below and shown in Fig. 2.

\section{Sample Preparation}

Hydrogels were cast directly into the round cavity of the sample holder, which was placed upside down on a piece of Parafilm and held in place with standard adhesive tape. $222 \mu \mathrm{l}$ of the $37{ }^{\circ} \mathrm{C}$ warm gelatin solution were pipetted through the lateral openings of the sample holder (see Fig. 2), until the $3 \mathrm{~mm}$ high edge of the sample holder and thus the desired sample thickness of $3 \mathrm{~mm}$ was reached. After five minutes at room temperature $\left(22.3{ }^{\circ} \mathrm{C}\right)$, the samples were carefully transferred into a refrigerator and cooled for $5 \mathrm{~min}$ at $4{ }^{\circ} \mathrm{C}$. Before LDV measurements, the Parafilm was removed, and the sample holder was mounted on a piezoelectric actuator in upright position, (P844.10, Physik Instrumente, Karlsruhe, Germany), where the sample was allowed to rest for $6 \mathrm{~min}$ to equilibrate and adapt to room temperature. To minimize possible sources of error, the same sample holder was used for all hydrogels investigated.

\section{LDV Measurements / Experimental Setup}

For the LDV measurements, a PSV-500 scanning vibrometer equipped with a NIR laser $(\lambda=1550 \mathrm{~nm})$, a PSV-A-410 closeup unit and a PSV-A-CL-200-Xtra micro scan lens (Polytec $\mathrm{GmbH}$, Waldbronn, Germany) was used. The green pilot laser was focused onto the rim of the sample holder and 20 measurement points were defined in a circular arrangement in the user interface. On the surface of the gelatin sample itself in total 31 measurement points were defined. As focus value, the values of the sample holder were assigned, because it turned out to be more difficult and error-prone to focus directly onto the transparent hydrogel surface. For excitation of the preloaded piezo with a periodic chirp sweep from 0 to $2.5 \mathrm{kHz}$ (sweep rate of $640 \mathrm{~ms}$ ), the built-in signal generator of the LDV, together with a HiFi-amplifier (AV-235IS, electronic Toys Trading GmbH, Braunschweig, Germany) were used.
The obtained frequency resolution of the measurements was $1.56 \mathrm{~Hz}$.

\section{LDV Data Analysis}

The transmissibility was calculated by normalizing the data of the central measurement point on the hydrogel with respect to the mean value of all the data acquired on the rim of the sample holder. Analysis of resonance frequencies and full width at half maximum (FWHM) was done using MATLAB (The Mathworks Inc., Natick, Massachusetts, USA) and the findpeaks function. The damping constant $\gamma$ and the damping ratio $\zeta$ were derived from the full width at half maximum of the transmissibility squared $\Delta f_{F W H M}\left(T^{2}\right)$ using the following equations:

$\gamma=\pi \cdot \Delta f_{F W H M}\left(T^{2}\right)$

and

$\zeta=\frac{\gamma}{2 \pi \cdot f_{0,1}}=\frac{\Delta f_{F W H M}\left(T^{2}\right)}{2 f_{0,1}}$

where $T$ is the transmissibility and $f_{0,1}$ the resonance frequency (in $\mathrm{Hz}$ ) of the $(0,1)$ mode.

\section{AFM Measurements}

IT-AFM measurements were carried out with a NanoWizard I AFM (JPK Instruments, Berlin, Germany), with a maximum lateral scan range of $100 \times 100 \mu \mathrm{m}^{2}$, and a vertical range of $15 \mu \mathrm{m}$. The setup was positioned on a granite slab suspended with bungee cords inside a soundproof box to reduce external noise. For the IT-AFM measurements, silicon nitride cantilevers (MLCT Cantilever E, Bruker, Mannheim, Germany) with a nominal spring constant of $0.1 \mathrm{~N} / \mathrm{m}$ and pyramidal tips with a nominal radius of $20 \mathrm{~nm}$ were used. The tip velocity during the indentation experiments was always $12 \mu \mathrm{m} / \mathrm{s}$. For every cantilever, the actual spring constant was determined individually using the thermal noise method [52]. The spring constant calibration procedure was repeated three times, and the arithmetic average of the three values was used for data analysis. IT-AFM measurements were performed in phosphate-buffered saline at $\mathrm{pH}$ 7.4. On a $5 \times 5 \mu \mathrm{m}^{2}$ area, $10 \times 10$ force-indentation curves, consisting of 3330 data points each, were recorded. On every hydrogel, five force maps were acquired at different positions of the hydrogel surface.

\section{AFM Data Analysis}

The Young's modulus $E$ was extracted from the indentation part of the force curves by fitting the modified Hertz model for 
a pyramidal indenter [53], which gives the force $(F)$ as a function of the indentation depth $(d)$ :

$F(d)=\frac{E}{1-\nu^{2}} \cdot \frac{\tan (\alpha)}{2} \cdot d^{2}$

The Poisson's ratio $\nu$ was set to 0.5 for incompressible materials [54]; $\alpha$ is the half opening angle to an edge of the tip, which was $17.5^{\circ}$ for the used tips. All force curves were analyzed from the contact point up to an indentation depth of $1 \mu \mathrm{m}$, using the JPK Data Processing software (Version 6.1.42, JPK Instruments AG, Berlin, Germany). The Young's modulus values of all force-indentation curves were summarized in a stiffness distribution (histogram). To locate the maxima of these histograms, a Gaussian distribution was fitted to each histogram using the Igor Pro software (Version 6.3.4.0, WaveMetrics, Oregon, USA).

\section{Unconfined Compression Testing}

For unconfined compression testing, a mechanical test system (MACH-1 v500cs, MA003, Biomomentum Inc., Laval, Canada) with a multiaxial load cell (70 N, MA235, Biomomentum Inc., Laval, Canada) and a flat indenter (diameter: 12.5 mm, MA262, Biomomentum Inc., Laval, Canada) was used. Cylindrical gelatin samples with a mean height of $6.18 \mathrm{~mm}$ and a diameter of $7.7 \mathrm{~mm}$ were prepared using a 3Dprinted mold. The height was evaluated for each sample manually with a digital caliper ruler. The total compression length $l$ was set to $927 \mu \mathrm{m}$, corresponding to a maximum strain of $15 \%$. The compression velocity was $139 \mu \mathrm{m} / \mathrm{s}$, corresponding to a strain-rate of $2.3 \% / \mathrm{s}$. For each gelatin concentration, five samples were tested. The error bars in Fig. 5 represent standard deviations.

\section{Data Analysis Unconfined Compression Testing}

The Young's modulus $E$ was extracted from the slope of the linear part of the stress-strain-curves (10-15\% strain) obtained by unconfined compression testing, using $E=\frac{\Delta F \cdot h}{\Delta l \cdot A}$, where $\Delta F / \Delta l$ is the slope of the force compression curve, $h$ is the sample height and $A$ is the surface area (see also Supplementary Fig. 3).

\section{Analytical Model for Modal Analysis of a Vibrating Disk}

To analytically extract Young's modulus values from the experimentally determined eigenfrequencies of the $(0,1)$ mode and compare them to IT-AFM and confined compression testing, we used a linear elastic model of a clamped vibrating disc $[55,56]$. For a thin disc the frequency of the $(0,1)$ mode is given by: $f_{0,1}=\frac{\beta_{0,1}^{2}}{2 \pi} c \sqrt{\frac{D}{\rho_{A}}}$, with $\beta_{0,1}=\frac{1.015 \cdot \pi}{r}$

where $r$ is the radius of the disc, in our case $4.85 \mathrm{~mm}, D$ $=\frac{E h^{3}}{12\left(1-\nu^{2}\right)}$ is the plate bending stiffness, $\rho_{A}=\rho h$, the area density of the disc (see Supplementary Material for the concentration dependent mass densities $\rho$ ) and $h$ the disc thickness, here $3 \mathrm{~mm}$. In this equation $\mathrm{c}$ is a geometrical correction factor, which is 1 in the case of thin discs $(r / h » 10)$. In our case, where $r / h \approx 1.6$, c becomes 0.59 [57]. Because Eq. 5 describes a vibrating disc without energy dissipation, we used

$f_{0,1}=\frac{f_{0,1}^{L D V}}{\sqrt{1-\zeta^{2}}}$

to derive $f_{0,1}$ from the first eigenfrequencies determined by $\operatorname{LDV}\left(f_{0,1}^{L D V}\right)[58]$.

\section{Finite Element Method Analysis}

To numerically extract the Young's modulus values from the LDV resonance frequencies, we applied the finite element method, using COMSOL Multiphysics software (version 4.3b, COMSOL AB, Stockholm, Sweden) and a threedimensional solid mechanics model for calculating the eigenfrequenies $f_{0,1}^{F E M}$. The meshing method was set to physics-controlled using the element size "finer". In the FEM, the mass density and Young's modulus were set to 1 and the Poisson's ratio to 0.499 . The Young's modulus of the gelatin used in the experiments was then evaluated from

$E=\left(\frac{f_{0,1}}{f_{0,1}^{F E M}}\right)^{2} \cdot \rho$

where the (un-damped) resonance frequency $f_{0,1}$ was again derived from the LDV data using Eq. 6, and the experimentally determined gelatin densities (see Supplementary Table 2) were used for $\rho$.

\section{Results}

\section{Determining the Absorption Coefficient of Gelatin Hydrogels at the LDV Wavelength}

To investigate whether the mechanical properties of transparent hydrogels can, in fact, be determined without additional reflective coatings or markers with a NIR laser, we first confirmed that the detected signal indeed originates from the hydrogel surface pointing towards the LDV and is not reflected 
from the backside of the hydrogel or other reflective or partially reflective surfaces behind the gel. We therefore determined the absorption coefficient of a $0.20 \mathrm{~g} / \mathrm{ml}$ gelatin hydrogel at the laser wavelength of $\lambda=1550 \mathrm{~nm}$, by measuring the transmitted intensity of the LDV laser as a function of gelatin thickness (see methods section for details). As expected, the transmitted laser intensity decreases exponentially between $1 \mathrm{~mm}$ and $6 \mathrm{~mm}$ gelatin thickness, following LambertBeer's law and yielding an absorption coefficient of $\alpha=$ $1.012 / \mathrm{mm}$ (see Fig. 1). We subsequently chose a sample thickness of $3 \mathrm{~mm}$ for all further investigations, because this thickness leads to a more than 400-fold reduction in light intensity for laser light which might be reflected from the backside or from behind the hydrogel sample, and which has to pass through the $3 \mathrm{~mm}$ sample twice, thereby ensuring that in our vibrational analysis of the samples, the detected LDV signal originates mainly from the proximal hydrogel surface. At the same time, this sample thickness provides sufficient mechanical stability to ensure stable measurement conditions and allows for reliable detection of the eigenmodes of the oscillating samples (see below).

\section{Integrating the Hydrogel Samples in the LDV Setup}

For dynamic excitation, $3 \mathrm{~mm}$ thick gelatin discs (diameter $9.7 \mathrm{~mm}$ ) were suspended inside a cylindrical sample holder. To ensure good mechanical contact between the hydrogel and the sample holder rim and obtain a smooth hydrogel surface which reflects as much light as possible back to the LDV detector, the liquid gelatin solution was cast directly into the sample holder, and then mounted on a piezoelectric actuator (see Fig. 2, and methods section for details of the sample preparation). The LDV was positioned approximately $0.2 \mathrm{~m}$ above the sample and manually focused onto the rim of the sample holder, with the help of a green pilot laser $(\lambda=$ $520 \mathrm{~nm}$ ). Because the liquid gelatin had been cast directly into the sample holder, the rim of the sample holder was always coplanar with the hydrogel surface, and focusing the laser on the sample holder rim was thus sufficient to define the measurement plane on the hydrogel surface.

\section{Measuring Hydrogels with the LDV}

After defining 20 measurement points on the sample holder and 31 measurement points on the hydrogel surface (see Fig. 2 and Fig. 3), the piezo actuator was dynamically excited by sweeping a periodic chirp signal from 0 to $2.5 \mathrm{kHz}$, as depicted schematically in Fig. 3. We then used the NIR scanning laser $(\lambda=1550 \mathrm{~nm})$, to determine amplitude, phase and deflection shape of the resulting oscillations of the hydrogel and sample holder (see methods section for details).

Figure 4a shows the velocity amplitude of an oscillating $0.20 \mathrm{~g} / \mathrm{ml}$ gelatin hydrogel at the central position of the sample (blue line) together with the velocity amplitude of the sample holder (orange line) as a function of the excitation frequency. At a frequency of $223 \mathrm{~Hz}$, the first resonance can be observed, followed by peaks at $544 \mathrm{~Hz}, 952 \mathrm{~Hz}$, and $1311 \mathrm{~Hz}$. The first resonance of the sample holder appears at $1117 \mathrm{~Hz}$. Scanning the sample in 2D revealed that the first resonance peak at $223 \mathrm{~Hz}$ corresponds to the first fundamental mode, i.e. the $(0,1)$ mode of the gelatin disc (see Supplementary Fig. 1 and Supplementary video). The resonances at $544 \mathrm{~Hz}$ and $952 \mathrm{~Hz}$ correspond to modes with zero displacement in the center of the disc $(0,2$ and 1,1$)$ as revealed by $2 \mathrm{D}$ scanning of the sample (see Supplementary Fig. 1b-d). They should therefore not appear in the frequency response in Fig. 4.a. Nevertheless, these peaks are present, probably because the setup was not
Fig. 1 Absorption of the LDVlaser in gelatin. Optical transmission of $0.20 \mathrm{~g} / \mathrm{ml}$ gelatin samples with varying thickness (blue dots) in a semi-logarithmic representation, together with an exponential fit (black dotted line), yielding an absorption coefficient $\alpha=1.0121 / \mathrm{mm}$. Without gelatin sample $(0 \mathrm{~mm})$, the laser intensity was $8.92 \mathrm{~mW}$. Error bars represent standard deviation.

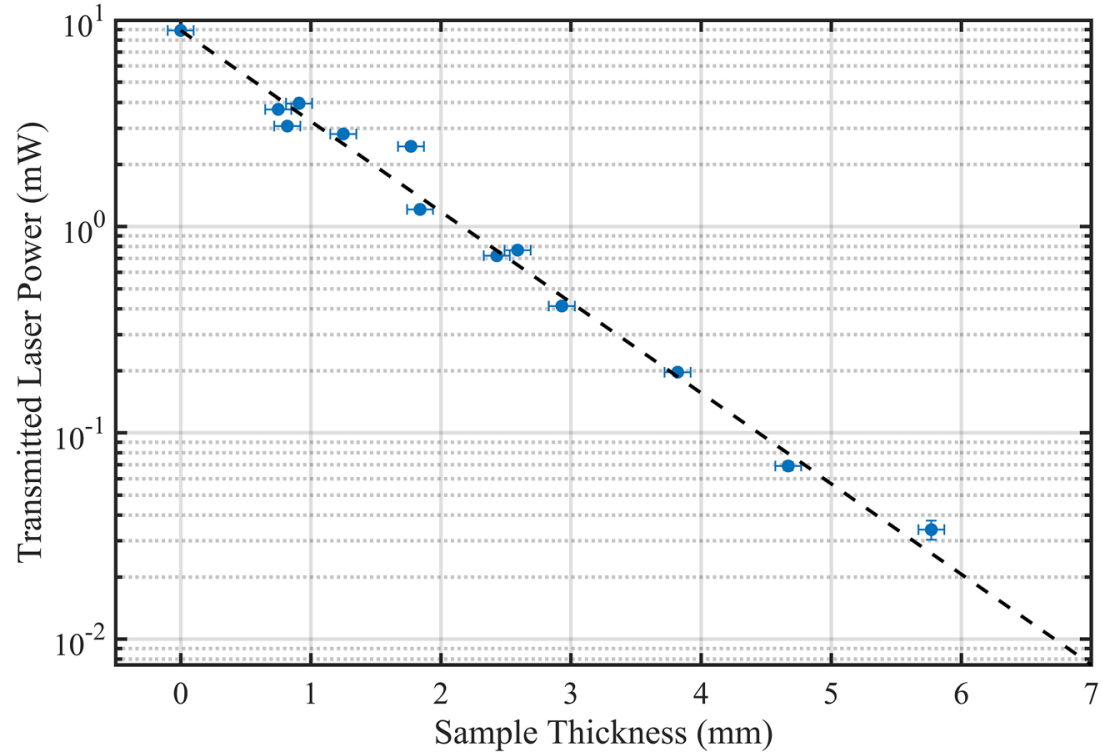




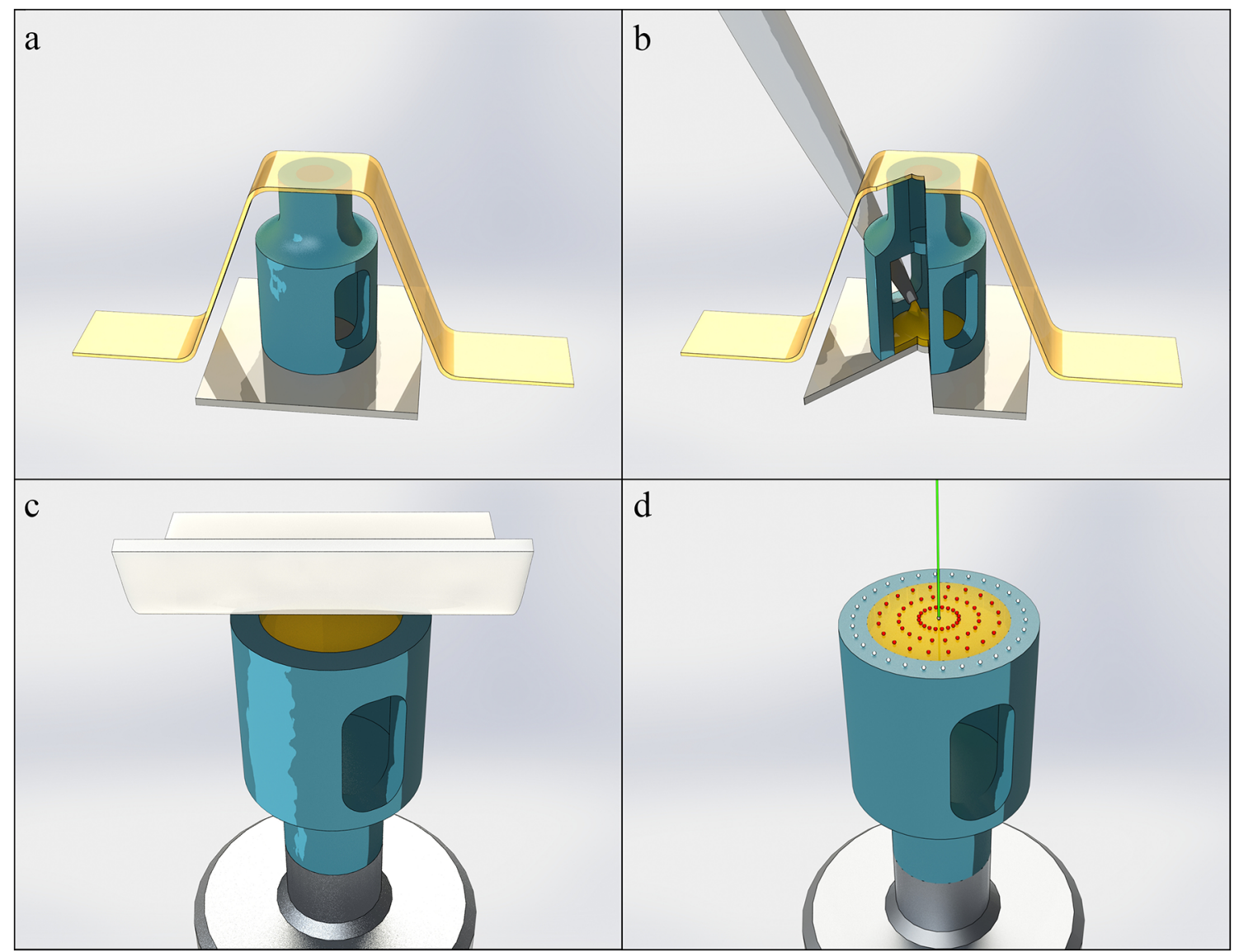

Fig. 2 Preparation and mounting of the gelatin sample on the piezo actuator. a, The sample holder (blue) is fixed upside down on Parafilm (white) and held in place with adhesive tape (yellow). b, Liquid gelatin is pipetted into the cavity of the sample holder until a gelatin level of $3 \mathrm{~mm}$ is reached. $\mathbf{c}$, After gelation of the sample, the sample holder is screwed directly onto the stack piezo (grey), and the Parafilm is removed. d, A visible pilot laser (green) is focused on the rim of the sample holder and measurement (red dots) and reference points (white dots) are defined on the gelatin sample and the sample holder rim.

perfectly axisymmetric and the measurement point was not perfectly in the center of the sample.

\section{Vibrational Analysis of Hydrogel Samples}

For the further analysis of hydrogels with different gelatin concentrations, we focused solely on the first fundamental mode and divided the velocity amplitude of the gel by the velocity amplitude determined at the sample holder rim, to obtain the transmissibility of the sample, which is depicted in Fig. $4 \mathrm{~b}$ for gels with seven different gelatin concentrations. Again, all spectra were recorded at the central position of the respective gelatin disc. The $0.10 \mathrm{~g} / \mathrm{ml}$ gelatin gel (yellow line) exhibits its first resonance at $144 \mathrm{~Hz}$, with a maximum transmissibility of 23.73 and a width of the resonance curve of $10 \mathrm{~Hz}$ (full width at half maximum). With increasing gelatin concentration (steps of $0.05 \mathrm{~g} / \mathrm{ml}$, from $0.10 \mathrm{~g} / \mathrm{ml}$ up to $0.40 \mathrm{~g} /$ $\mathrm{ml}$ ), the first resonance moves to higher frequencies, reaching $486 \mathrm{~Hz}$ for the $0.40 \mathrm{~g} / \mathrm{ml}$ gelatin gel (see Supplementary Table 1 for the exact values at all gelatin concentrations). At the same time, the transmissibility of the $(0,1)$ mode decreases, and the width of the resonance curve relative to the peak height increases with increasing gelatin concentration, pointing to increased internal energy dissipation at higher gelatin concentrations and frequencies. Fig. $4 \mathrm{c}$ summarizes the results of Fig. $4 \mathrm{~b}$, and displays the frequencies $f_{0,1}^{L D V}$ of the first fundamental mode $(0,1)$ for all seven gelatin hydrogels (blue dots, left axis), together with the damping ratio $\zeta$ (insert in Fig. 4c, see methods section for details of the calculation). Both the eigenfrequency of the $(0,1)$ mode and the damping ratio increase with gelatin concentration, indicating that elastic modulus and viscous damping increase with increasing gelatin concentrations. In addition to the damping ratio, we also extracted the damping constant $\gamma$ from the data, which is proportional to the viscosity of the gel and grows exponentially with gelatin concentration, as reported in the literature (Supplementary Fig. 2, see methods section for details or the calculation) [59-61].

To directly correlate the eigenfrequencies of the $(0,1)$ mode to the elastic moduli of the gelatin gels, we determined the Young's moduli of all seven gels using ITAFM (orange dots in Fig. 4c, right axis). The Young's 
Fig. 3 Measuring hydrogels with the LDV. Schematic representation of the experimental setup, with the scanning LDV above the gelatin sample, which is fixed inside the cylindrical sample holder and excited with a sinusoidal chirp signal $(0$ $2.5 \mathrm{kHz}$ ) generated by the control unit and amplified by a HiFi amplifier (not shown).

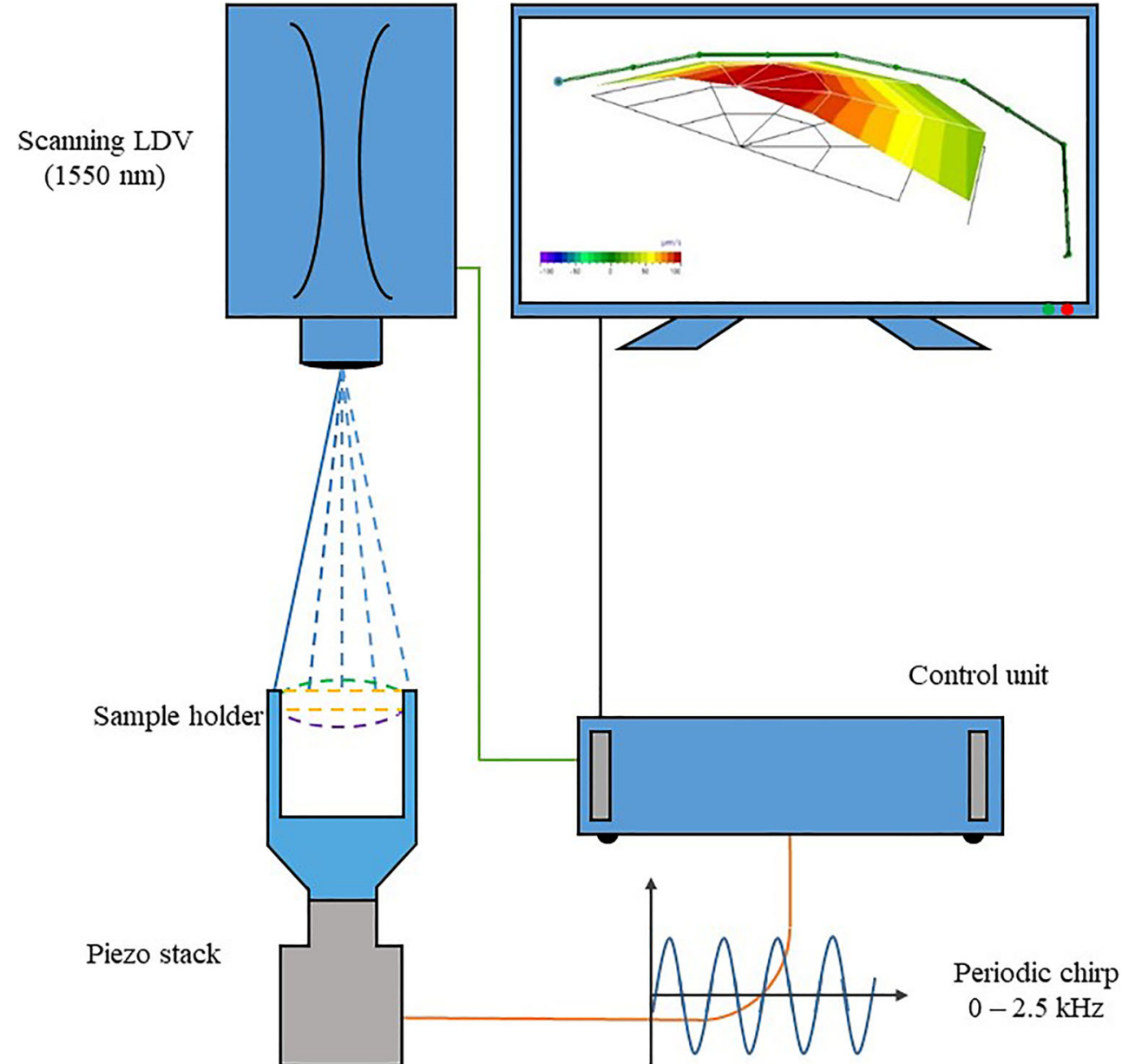

moduli span a range from $2.06 \mathrm{kPa}$ for the $0.10 \mathrm{~g} / \mathrm{ml}$ gelatin gel up to $33.95 \mathrm{kPa}$ for $0.40 \mathrm{~g} / \mathrm{ml}$ gelatin. Within error limits, the Young's moduli show an almost linear increase with the gelatin concentration, which is in accordance with the literature $[62,63]$. Here we excluded the last data point at $0.40 \mathrm{~g} / \mathrm{ml}$ from the linear fit, because its Young's modulus is lower than that at $0.35 \mathrm{~g} / \mathrm{ml}$. At $0.40 \mathrm{~g} / \mathrm{ml}$ gelatin, we occasionally observed air bubbles in the hydrogel. We therefore assume that we accidentally carried out the AFM measurements in the vicinity or on top of an air bubble. In Fig. 4d, the eigenfrequencies of the $(0,1)$ mode are plotted vs. the square root of the Young's modulus determined by IT-AFM for the different gelatin concentrations. As indicated by the linear fit (dashed line in Fig. 4d), the eigenfrequency of the first fundamental $(0,1)$ mode increases approximately linearly with the square root of the Young's moduli, which is in agreement with linear elastic theory for the vibration of a homogeneous disc structure [56], indicating that it might even be possible to extract the Young's modulus values directly from the LDV data, with a modal analysis.

To investigate if a modal analysis can indeed be used to extract the Young's moduli directly from the LDV data, we used an analytical elastic model of a clamped vibrating disc [55, 57], as well as FEM analysis (see sections 2.11 and 2.12 for details). Using the thin disc approximation of the analytical model $(\mathrm{c}=1$ in Eq. 5), we obtain a reasonable agreement between the Young's moduli derived from LDV resonance frequencies (blue data points in Fig. 5) and the IT-AFM results (orange data points in Fig. 5). Only the $0.40 \mathrm{~g} / \mathrm{ml}$ AFM value had to be excluded, for the same reason given above. However, when we use the correction factor for a "thick" disc with $9.8 \mathrm{~mm}$ diameter and $3 \mathrm{~mm}$ thickness $(\mathrm{c}=0.59$, yellow data points in Fig. 5), the LDV derived results increase almost threefold and no longer agree with the AFM data. Using FEM analysis to derive Young's moduli from the LDV data (green data points in Fig. 5) renders comparable values, which are again approximately three times higher than the IT-AFM values.

However, IT-AFM deforms the gelatin hydrogels only locally at the sample surface (in our case the indentation depth was approx. $800 \mathrm{~nm}$ ), while upon dynamic excitation, for example of the $(0,1)$ mode, the entire hydrogel disc undergoes periodic deformation. For polymer based hydrogels, such as gelatin, it is well known that due to the 

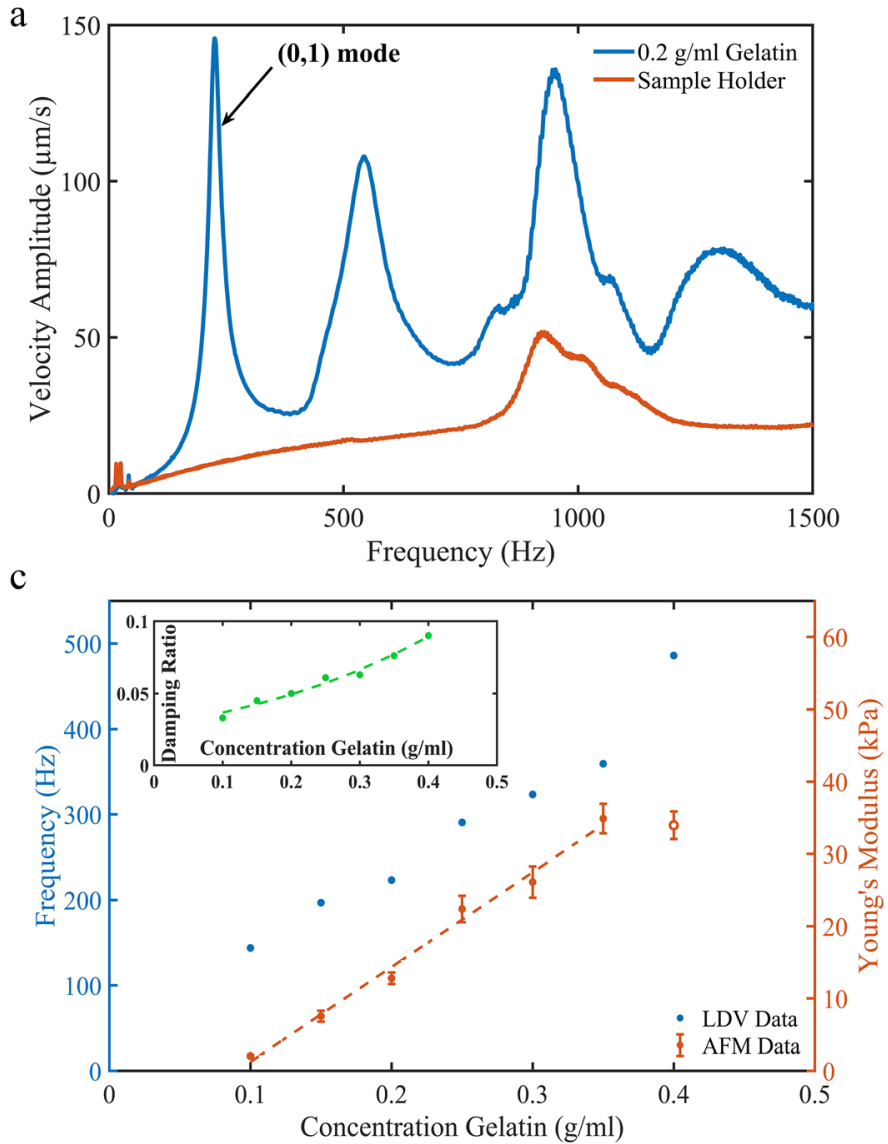

b

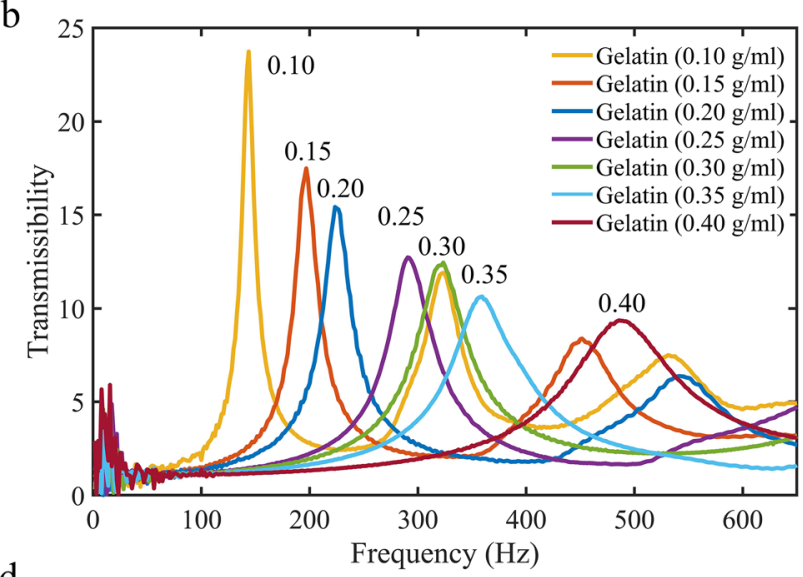

d

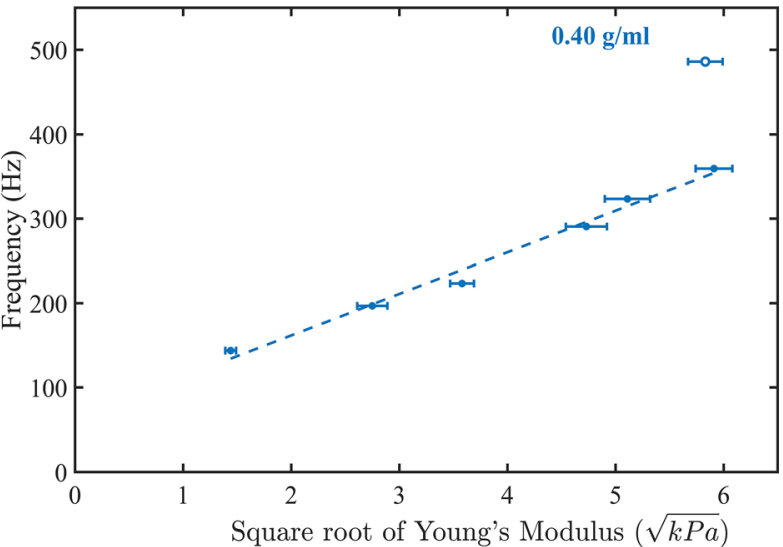

Fig. 4 Resonance frequencies, damping coefficients, and Young's moduli of the gels. a, Velocity amplitude at the central position of the $0.20 \mathrm{~g} / \mathrm{ml}$ gelatin sample (blue line) and the mean velocity amplitude of the sample holder rim (orange line), with the first resonance peaks of the gelatin and sample holder at $223 \mathrm{~Hz}$ and $1117 \mathrm{~Hz}$, respectively. b. Transmissibility of samples with gelatin concentrations from $0.10-0.40 \mathrm{~g} / \mathrm{ml}$ at the central position of the samples. The velocity amplitude was determined at the central position of each sample, and normalized with respect to the mean velocity amplitude of the sample holder rim, which was simultaneously determined, in order to obtain the transmissibility. The frequency of the $(0,1)$ mode is clearly visible for all gelatin concentrations. c, Resonance frequencies (blue dots, right axis), Young's modulus values determined by IT-AFM (orange dots, left axis), and damping ratio of the $(0,1)$ mode of the hydrogels (insert) vs. the gelatin concentration $\mathbf{d}$, Eigenfrequencies of the $(0,1)$ mode of the gelatin discs vs. the Young's modulus values. For IT-AFM standard deviations are given.

non-linear entropic elasticity of the individual polymers, the material responds to strain in a highly non-linear way, leading to a strain-dependent Young's modulus and strain stiffening [64], i.e. the Young's modulus increases with increasing strain. In addition to IT-AFM we therefore also carried out unconfined compression tests, where the entire gelatin samples were compressed up to $15 \%$ (see section 2.9). These tests revealed the expected non-linear forceresponse of gelatin to strain, where the Young's modulus increases with strain, before it reaches a plateau at $\sim 10$ 15\%, strain (see Supplementary Fig. 3). As can be seen in Fig. 5 (purple data points), the results of these unconstrained compression tests agree much better with the "thick" disc analytical model $(c=0.59)$ and with the FEM results (green data points), indicating that the (global) unconfined compression of entire hydrogel samples represents the deformations experienced by the samples during dynamic excitation much better, than the (local) $\sim 800 \mathrm{~nm}$ indentation of the pyramidal AFM tip.

\section{Discussion}

One major problem in the vibrational analysis of transparent hydrogels by LDV is the low reflectivity of the hydrogel surface. For the gelatin hydrogels, with a refractive index of water at the laser wavelength $(1550 \mathrm{~nm})$ of $n_{\mathrm{H}_{2} \mathrm{O}}=1.318$, and an incremental refractive index of gelatin $\alpha_{g}=0.18$, the total refractive index is only 1.35 for the $0.10 \mathrm{~g} / \mathrm{ml}$ gelatin hydrogel and 1.39 for the $0.40 \mathrm{~g} / \mathrm{ml}$ gelatin gel [65-67]. As a consequence, only about $2.2 \%$ (for $0.10 \mathrm{~g} / \mathrm{ml}$ ) to $2.7 \%$ (for $0.40 \mathrm{~g} /$ $\mathrm{ml}$ ) of the incoming laser intensity is reflected back from the air-hydrogel interface at normal incidence (see Supplementary Table 3 for details of the calculation of refractive index and 
Fig. 5 Young's moduli obtained using a linear elastic model for a thin gelatin disc (blue data points), a thick gelatin disc (yellow data point) and FEM (green data points). Experimental determined Young's moduli obtained by IT-AFM (orange data points) and unconfined compression testing (purple data points). All Young's moduli are plotted versus the gelatin concentration. Error bars of IT-AFM data and of unconfined compression testing represent standard deviations. For errors of the analytical and the FEM models, an uncertainty of $0.1 \mathrm{~mm}$ was assumed regarding the disc thickness.

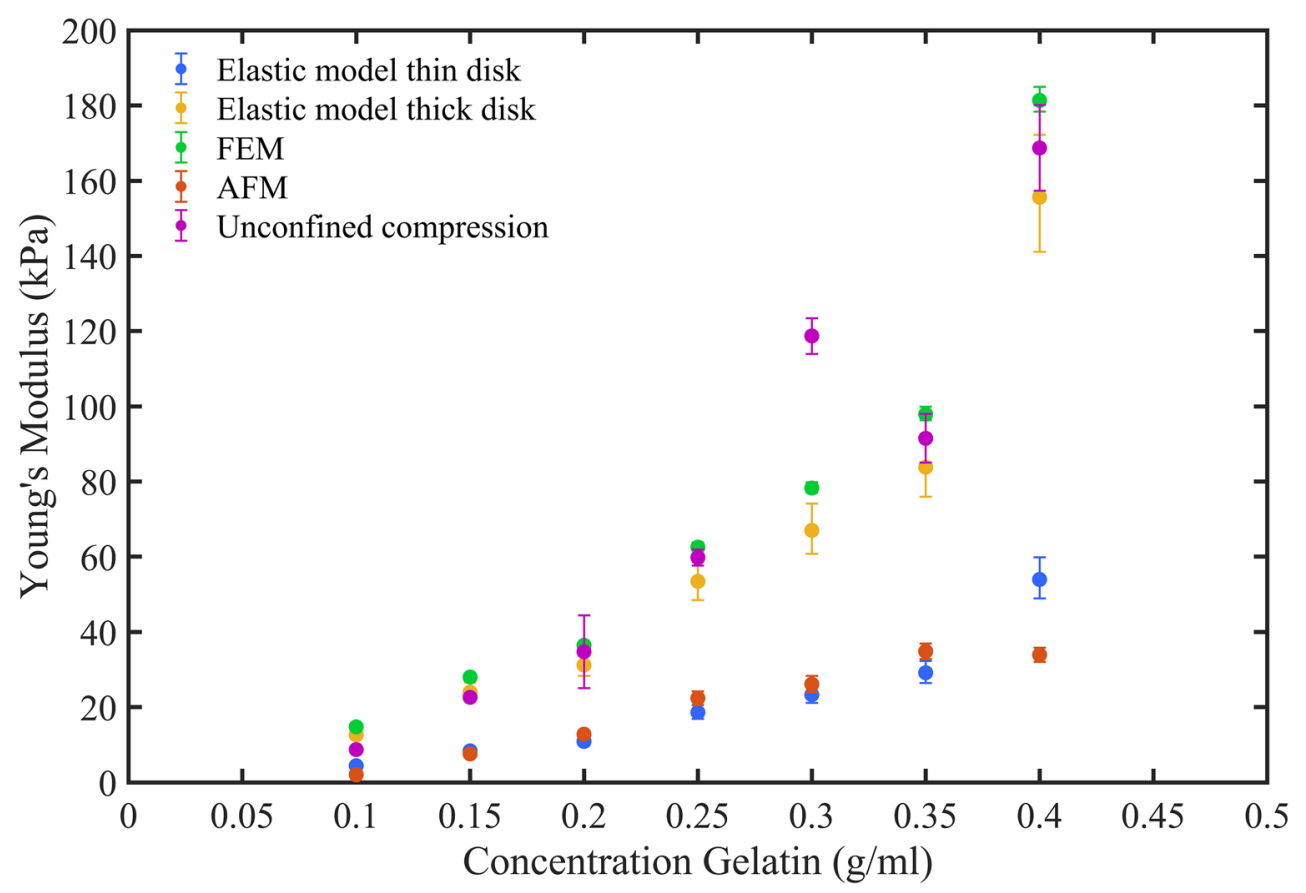

reflectivity). Nevertheless, because of the frequency modulation detection technique used by the LDV interferometer, this signal is still high enough to permit LDV measurements at a sufficient signal to noise ratio, provided that even less laserlight from behind the transparent samples reached the LDV detector. However, for fully transparent gels, the intensity of laser light which is reflected from the backside of the hydrogel would be nearly identical to the intensity reflected from the front side, and light which is reflected by other possibly more reflective surfaces behind the hydrogel can potentially have a much higher intensity than the measurement signal from the front side of the gel. For this reason, we chose the laser wavelength $\lambda=1550 \mathrm{~nm}$ for our investigation. At this wavelength, the absorption coefficient of water is about 3 orders of magnitude larger than in the visible range $[65,68]$, and therefore, unlike in the visible range, the intensity of light which is reflected or scattered back from the backside or surfaces behind the hydrogel, and which could potentially disturb the measurement, is sufficiently reduced. As already mentioned, with an absorption coefficient of the $0.20 \mathrm{~g} / \mathrm{ml}$ gelatin hydrogel of $1.012 / \mathrm{mm}$ at $\lambda=1550 \mathrm{~nm}$ (see Fig. 1), for the $3 \mathrm{~mm}$ thick gelatin samples investigated in our study, the intensity of laser light which passes through the gel twice before it reaches the detector of the LDV, is reduced more than 400 -fold, ensuring that the measured signal originates mainly from the front side of the hydrogel surface. Although the gelatin gels have been thoroughly homogenized, back-scattering by molecular structures inside the hydrogel cannot be ruled out entirely. However, the refractive index increment at the air hydrogel interface is significantly larger than any refractive index increments expected inside the hydrogels [65, 69] (see also SI for the concentration-dependent refractive index of gelatin hydrogels). In addition, the measurement spot of the LDV is focused on the front side of the gel. This reduces possible background signals from out of focus areas even further, and for future applications, one might even envision using a confocal LDV setup to minimize background signals [70], as long as the focal depth is large enough to allow detection of the entire oscillation amplitude.

In the vibrational analysis of the $0.20 \mathrm{~g} / \mathrm{ml}$ gelatin hydrogel (Fig. 4a), we can clearly distinguish the three fundamental modes $(0,1),(1,1)$, and $(1,2)$ of the gelatin disc (see Supplementary Fig. 1), which confirms the validity of our approach and shows that it is possible to conduct vibrational analysis on transparent hydrogel structures with an LDV, provided that a NIR laser is used. We also find the expected square root dependence of the frequency of the first fundamental mode on the Young's modulus of the hydrogel (Fig. 4d) [55, 56]. Furthermore, in agreement with previous studies on gelatin viscosity [52-54], the damping constant increases exponentially with gelatin concentration (see Supplementary Fig. 2). Finally, a modal analysis with appropriate analytical modelling as well as FEM analysis, rendered even reasonable quantitative agreement between the LDV results and the bulk elastic modulus, as determined by unconfined compression testing. Taken together, these findings underpin the validity of the approach and demonstrate that, for the chosen geometry, it is possible to determine elastic material parameters of the hydrogel. It has to be pointed out, however, that our approach strongly depends on the geometry of the chosen setup, and that we were not able to determine the elastic modulus of the gels by measuring the transfer functions 
of gels placed directly on top of a vibrating solid support. It should also be pointed out that pre-strain stiffening of the hydrogel is only one possible explanation for the discrepancy between IT-AFM data and unconfined compression testing. An investigation of the strain dependence of the Young's modulus of gelatin hydrogels, especially for small deformations, as well as a systematic comparison between IT-AFM and unconstrained compression testing is still missing and should be carried out in future studies. Nevertheless, for production and quality control in a manufacturing process and many other applications, the detection of changes of the material properties, which have to reach a certain set-point, e.g. during gelation or the discovery of deviations from a desired set-point, is more important than the direct quantification of elastic parameters. Once the system has been properly set up, tested, and calibrated, a similar approach to the one shown here should therefore also be applicable to other geometries and setups, and the good agreement between LDV derived Young's moduli and the unconfined compression data indicates that, with more sophisticated numerical modeling, even complex geometries might be analyzed with LDV in the future.

\section{Conclusion}

In summary, our results clearly show the feasibility of the mechanical characterization of transparent hydrogel structures using LDV. With the chosen setup and geometry, we cannot only detect changes in the vibrational behavior of the investigated structures caused by changes in the material parameters, but we can also correlate the observed changes in the vibration spectra to the Young's modulus of the hydrogel. We envision a broad range of possible applications, from adhesives to food technology to the rapidly developing field of biofabrication, where this approach might be used in the manufacturing of cell-laden 3D hydrogel structures, as well as for monitoring the maturation of $3 \mathrm{D}$ tissue constructs in situ. In the future, this approach might be further improved by new LDV setups with even longer wavelengths, as well as by using confocal measurement geometries.

Acknowledgments We thank Stefan König, Marco Fritzsche and Dennis Berft for assistance with LDV measurements and data analysis, Jan Winter for assisting in measuring the transmitted laser intensities. The authors acknowledge financial support through the research focus "Herstellung und biophysikalische Charakterisierung dreidimensionaler Gewebe - CANTER" of the Bavarian State Ministry for Science and Art, the graduate program BayWISS Materials and Polytech for kindly providing the LDV setup. Open Access funding provided by Projekt DEAL.

Author's Contributions S. Schwarz carried out LDV, compression testing and optical measurements, analyzed data and wrote the manuscript. B. Hartmann carried out AFM experiments, analyzed AFM data and corrected the manuscript. Joerg Sauer helped to design the LDV experiments, analyze LDV data and corrected the manuscript. R. Burgkart conceived LDV measurements and corrected the manuscript. S. Sudhop designed and supervised LDV, compression testing and AFM experiments and helped to write the manuscript. D. Rixen designed and supervised LDV experiments and helped to write the manuscript. H. Clausen-Schaumann designed and supervised LDV, compression testing and AFM experiments and wrote the manuscript.

\section{Compliance with Ethical Standards}

The research conducted in this work did not involve human participants or animals.

The research was funded by the CANTER Research Focus of the Bavarian State Ministry for Science and Education

All authors have read and consented to the final version of the manuscript.

Conflict of Interests The authors declare no comnflict of interests.

Open Access This article is licensed under a Creative Commons Attribution 4.0 International License, which permits use, sharing, adaptation, distribution and reproduction in any medium or format, as long as you give appropriate credit to the original author(s) and the source, provide a link to the Creative Commons licence, and indicate if changes were made. The images or other third party material in this article are included in the article's Creative Commons licence, unless indicated otherwise in a credit line to the material. If material is not included in the article's Creative Commons licence and your intended use is not permitted by statutory regulation or exceeds the permitted use, you will need to obtain permission directly from the copyright holder. To view a copy of this licence, visit http://creativecommons.org/licenses/by/4.0/.

\section{References}

1. Godoi FC, Prakash S, Bhandari BR (2016) 3d printing technologies applied for food design: status and prospects. J Food Eng 179:44 54. https://doi.org/10.1016/j.jfoodeng.2016.01.025

2. Nicodemus GD, Bryant SJ (2008) Cell encapsulation in biodegradable hydrogels for tissue engineering applications. Tissue Eng Pt BRev 14(2):149-165. https://doi.org/10.1089/ten.teb.2007.0332

3. Zhang YS, Khademhosseini A (2017) Advances in engineering hydrogels. Science 356(6337):eaaf3627. https://doi.org/10.1126/ science.aaf3627

4. Van Vlierberghe S, Dubruel P, Schacht E (2011) Biopolymer-based hydrogels as scaffolds for tissue engineering applications: a review. Biomacromolecules 12(5):1387-1408. https://doi.org/10.1021/ bm200083n

5. Choi JR, Yong KW, Choi JY, Cowie AC (2019) Recent advances in photo-crosslinkable hydrogels for biomedical applications. Biotechniques 66(1):40-53. https://doi.org/10.2144/btn-2018-0083

6. Ventre M, Netti PA (2016) Controlling cell functions and fate with surfaces and hydrogels: the role of material features in cell adhesion and signal transduction. Gels 2 (12)

7. Holle AW, Young JL, Van Vliet KJ, Kamm RD, Discher D, Janmey P, Spatz JP, Saif T (2018) Cell-extracellular matrix Mechanobiology: forceful tools and emerging needs for basic and translational research. Nano Lett 18(1):1-8. https://doi.org/10. 1021/acs.nanolett.7b04982

8. Prein C, Warmbold N, Farkas Z, Schieker M, Aszodi A, ClausenSchaumann H (2016) Structural and mechanical properties of the proliferative zone of the developing murine growth plate cartilage 
assessed by atomic force microscopy. Matrix Biol 50:1-15. https:// doi.org/10.1016/j.matbio.2015.10.001

9. Discher DE, Smith L, Cho S, Colasurdo M, Garcia AJ, Safran S (2017) Matrix Mechanosensing: from scaling concepts in 'Omics data to mechanisms in the nucleus, regeneration, and Cancer. Annu Rev Biophys 46:295-315. https://doi.org/10.1146/annurevbiophys-062215-011206

10. Swift J, Ivanovska IL, Buxboim A, Harada T, Dingal PCDP, Pinter J, Pajerowski JD, Spinler KR, Shin JW, Tewari M, Rehfeldt F, Speicher DW, Discher DE (2013) Nuclear Lamin-a scales with tissue stiffness and enhances matrix-directed differentiation. Science 341(6149):1240104. https://doi.org/10.1126/science. 1240104

11. Vishwakarma M, Di Russo J, Probst D, Schwarz US, Das T, Spatz JP (2018) Mechanical interactions among followers determine the emergence of leaders in migrating epithelial cell collectives. Nat Commun 9:3469. https://doi.org/10.1038/s41467-018-05927-6

12. de la Loza MCD, Diaz-Torres A, Zurita F, Rosales-Nieves AE, Moeendarbary E, Franze K, Martin-Bermudo MD, GonzalezReyes A (2017) Laminin levels regulate tissue migration and anterior-posterior polarity during egg morphogenesis in drosophila. Cell Rep 20(1):211-223. https://doi.org/10.1016/j.celrep.2017.06. 031

13. Barriga EH, Franze K, Charras G, Mayor R (2018) Tissue stiffening coordinates morphogenesis by triggering collective cell migration in vivo. Nature 554 (7693):523-+. doi:https://doi.org/10.1038/ nature 25742

14. van Helvert S, Storm C, Friedl P (2018) Mechanoreciprocity in cell migration. Nat Cell Biol 20(1):8-20. https://doi.org/10.1038/ s41556-017-0012-0

15. Haeger A, Wolf K, Zegers MM, Friedl P (2015) Collective cell migration: guidance principles and hierarchies. Trends Cell Biol 25(9):556-566. https://doi.org/10.1016/j.tcb.2015.06.003

16. Yang B, Wolfenson H, Chung VY, Nakazawa N, Liu S, Hu J, Huang RY-J, Sheetz MP (2019) Stopping transformed cancer cell growth by rigidity sensing. Nat Mater 19:239-250. https://doi.org/ 10.1038/s41563-019-0507-0

17. Palamidessi A, Malinverno C, Frittoli E, Corallino S, Barbieri E, Sigismund S, Beznoussenko GV, Martini E, Garre M, Ferrara I, Tripodo C, Ascione F, Cavalcanti-Adam EA, Li QS, Di Fiore PP, Parazzoli D, Giavazzi F, Cerbino R, Scita G (2019) Unjamming overcomes kinetic and proliferation arrest in terminally differentiated cells and promotes collective motility of carcinoma. Nature materials 18 (11):1252-+. doi:https://doi.org/10.1038/s41563019-0425-1

18. Gegenfurtner FA, Jahn B, Wagner H, Ziegenhain C, Enard W, Geistlinger L, Radler JO, Vollmar AM, Zahler S (2018) Micropatterning as a tool to identify regulatory triggers and kinetics of actin-mediated endothelial mechanosensing. J Cell Sci 131(10): jcs212886. https://doi.org/10.1242/jcs.212886

19. Koser DE, Thompson AJ, Foster SK, Dwivedy A, Pillai EK, Sheridan GK, Svoboda H, Viana M, Costa LD, Guck J, Holt CE, Franze K (2016) Mechanosensing is critical for axon growth in the developing brain. Nat Neurosci 19(12):1592-1598. https://doi.org/ $10.1038 / \mathrm{nn} .4394$

20. Moeendarbary E, Weber IP, Sheridan GK, Koser DE, Soleman S, Haenzi B, Bradbury EJ, Fawcett J, Franze K (2017) The soft mechanical signature of glial scars in the central nervous system. Nat Commun 8. https://doi.org/10.1038/ncomms14787

21. Reuten R, Patel TR, McDougall M, Rama N, Nikodemus D, Gibert B, Delcros JG, Prein C, Meier M, Metzger S, Zhou Z, Kaltenberg J, Mckee KK, Bald T, Tuting T, Zigrino P, Djonov V, Bloch W, Clausen-Schaumann H, Poschl E, Yurchenco PD, Ehrbar M, Mehlen P, Stetefeld J, Koch M (2016) Structural decoding of netrin-4 reveals a regulatory function towards mature basement membranes. Nat Commun 7. https://doi.org/10.1038/ ncomms 13515

22. Paxton N, Smolan W, Bock T, Melchels F, Groll J, Jungst T (2017) Proposal to assess printability of bioinks for extrusion-based bioprinting and evaluation of rheological properties governing bioprintability. Biofabrication 9(4):044107. https://doi.org/10. 1088/1758-5090/aa8dd8

23. Highley CB, Rodell CB, Burdick JA (2015) Direct 3D printing of shear-thinning hydrogels into self-healing hydrogels. Adv mater 27 (34):5075-+. doi:https://doi.org/10.1002/adma.201501234

24. Melchels FPW, Blokzijl MM, Levato R, Peiffer QC, de Ruijter M, Hennink WE, Vermonden T, Malda J (2016) Hydrogel-based reinforcement of 3D bioprinted constructs. Biofabrication 8(3). https:// doi.org/10.1088/1758-5090/8/3/035004

25. Fiedler-Higgins CI, Cox LM, DelRio FW, Killgore JP (2019) Monitoring fast, voxel-scale cure kinetics via sample-coupledresonance Photorheology. Small Methods 3(2):1800275. https:// doi.org/10.1002/smtd.201800275

26. Malda J, Visser J, Melchels FP, Jungst T, Hennink WE, Dhert WJA, Groll J, Hutmacher DW (2013) 25th anniversary article: engineering hydrogels for biofabrication. Adv Mater 25(36): 5011-5028. https://doi.org/10.1002/adma.201302042

27. Kiderlen S, Polzer C, Radler JO, Docheva D, Clausen-Schaumann H, Sudhop S (2019) Age related changes in cell stiffness of tendon stem/progenitor cells and a rejuvenating effect of ROCK-inhibition. Biochem Bioph Res Co 509(3):839-844. https://doi.org/10.1016/j. bbrc.2019.01.027

28. Lv S, Dudek DM, Cao Y, Balamurali MM, Gosline J, Li HB (2010) Designed biomaterials to mimic the mechanical properties of muscles. Nature 465(7294):69-73. https://doi.org/10.1038/nature09024

29. Alsteens D, Muller DJ, Dufrene YF (2017) Multiparametric atomic force microscopy imaging of biomolecular and cellular systems. Accounts Chem Res 50(4):924-931. https://doi.org/10.1021/acs. accounts.6b00638

30. Babu PKV, Rianna C, Mirastschijski U, Radmacher M (2019) Nano-mechanical mapping of interdependent cell and ECM mechanics by AFM force spectroscopy. Sci Rep-Uk 9:12317. https:// doi.org/10.1038/s41598-019-48566-7

31. Rothberg SJ, Allen MS, Castellini P, Di Maio D, Dirckx JJJ, Ewins DJ, Halkon BJ, Muyshondt P, Paone N, Ryan T, Steger H, Tomasini EP, Vanlanduit S, Vignola JF (2017) An international review of laser Doppler vibrometry: making light work of vibration measurement. Opt Laser Eng 99:11-22. https://doi.org/10.1016/j. optlaseng.2016.10.023

32. Castellini P, Martarelli M, Tomasini EP (2006) Laser Doppler Vibrometry: development of advanced solutions answering to technology's needs. Mech Syst Signal Pr 20(6):1265-1285. https://doi.org/10.1016/j.ymssp.2005.11.015

33. Ferris P, Prendergast PJ (2000) Middle-ear dynamics before and after ossicular replacement. J Biomech 33(5):581-590. https://doi. org/10.1016/S0021-9290(99)00213-4

34. Ozbek M, Rixen DJ (2014) Aero-elastic parameter estimation of a 2.5 MW wind turbine through dynamic analysis of in-operation vibration data. ENEFM2013:279-285

35. Ohler B (2007) Cantilever spring constant calibration using laser Doppler vibrometry. Rev Sci Instrum 78(6):063701. https://doi.org/ 10.1063/1.2743272

36. Gates RS, Pratt JR (2012) Accurate and precise calibration of AFM cantilever spring constants using laser Doppler vibrometry. Nanotechnology 23(37):375702. https://doi.org/10.1088/0957$4484 / 23 / 37 / 375702$

37. Terasaki S, Sakurai N, Zebrowski J, Murayama H, Yamamoto R, Nevins DJ (2006) Laser Doppler vibrometer analysis of changes in elastic properties of ripening 'La France' pears after postharvest storage. Postharvest Biol Tec 42(2):198-207. https://doi.org/10. 1016/j.postharvbio.2006.06.007 
38. Muramatsu N, Sakurai N, Wada N, Yamamoto R, Tanaka K, Asakura T, Ishikawa-Takano Y, Nevins DJ (2000) Remote sensing of fruit textural changes with a laser Doppler vibrometer. J am Soc Hortic Sci 125 (1):120-127. Doi:https://doi.org/10.21273/Jashs. 125.1.120

39. Labelle L, Roozen NB, Vandenbroeck J, Akasaka S, Glorieux C (2017) Elastic characterization of polymer fibers by laser Doppler vibrometry. Opt Laser Eng 99:88-97. https://doi.org/10.1016/j. optlaseng.2016.11.020

40. Schuurman T, Rixen DJ, Swenne CA, Hinnen JW (2013) Feasibility of laser Doppler Vibrometry as potential diagnostic tool for patients with abdominal aortic aneurysms. J Biomech 46(6): 1113-1120. https://doi.org/10.1016/j.jbiomech.2013.01.013

41. Xu G, Wang C, Feng T, Oliver DE, Wang XD (2014) Non-contact Photoacoustic tomography with a laser Doppler Vibrometer. Proc SPIE 8943. https://doi.org/10.1117/12.2040290

42. Urban MW, Silva GT, Fatemi M, Greenleaf JF (2006) Multifrequency vibro-acoustography. Ieee T Med Imaging 25(10):1284-1295. https://doi.org/10.1109/Tmi.2006.882142

43. Meral FC, Royston TJ, Magin R (2010) Fractional calculus in viscoelasticity: an experimental study. Commun Nonlinear Sci 15(4): 939-945. https://doi.org/10.1016/j.cnsns.2009.05.004

44. Lawrence EM, Speller KE, Yu DL (2003) MEMS characterization using laser Doppler vibrometry. P Soc Photo-Opt Ins 4980:51-62. https://doi.org/10.1117/12.478195

45. Rembe C, Kant R, Muller RS (2001) Optical measurement methods to study dynamic behavior in MEMS. P Soc Photo-Opt Ins 4400: 127-137. https://doi.org/10.1117/12.445595

46. Gronau T, Kruger K, Prein C, Aszodi A, Gronau I, Iozzo RV, Mooren FC, Clausen-Schaumann H, Bertrand J, Pap T, Bruckner P, Dreier R (2017) Forced exercise-induced osteoarthritis is attenuated in mice lacking the small leucine-rich proteoglycan decorin. Ann Rheum Dis 76(2):442-449. https://doi.org/10.1136/ annrheumdis-2016-209319

47. Riessen HP, Linley RD, Altshuler I, Rabus M, Sollradl T, ClausenSchaumann H, Laforsch C, Yan ND (2012) Changes in water chemistry can disable plankton prey defenses. P Natl Acad Sci USA 109(38):15377-15382. https://doi.org/10.1073/pnas. 1209938109

48. Docheva D, Padula D, Popov C, Mutschler W, ClausenSchaumann H, Schieker M (2008) Researching into the cellular shape, volume and elasticity of mesenchymal stem cells, osteoblasts and osteosarcoma cells by atomic force microscopy. J Cell Mol Med 12(2):537-552. https://doi.org/10.1111/j.1582-4934. 2007.00138.x

49. Oyen ML (2014) Mechanical characterisation of hydrogel materials. Int Mater Rev 59(1):44-59. https://doi.org/10.1179/ 1743280413Y.0000000022

50. Marchi G, Baier V, Alberton P, Foehr P, Burgkart R, Aszodi A, Clausen-Schaumann H, Roths J (2017) Microindentation sensor system based on an optical fiber Bragg grating for the mechanical characterization of articular cartilage by stress-relaxation. Sensors Actuators B Chem 252:440-449. https://doi.org/10.1016/j.snb. 2017.05.156

51. Soulhat J, Buschmann MD, Shirazi-Adl A (1999) A fibril-networkreinforced biphasic model of cartilage in unconfined compression. $\mathrm{J}$ Biomech Eng 121(3):340-347. https://doi.org/10.1115/1.2798330

52. Hutter JL, Bechhoefer J (1993) Calibration of atomic-force microscope tips (Vol 64, Pg 1868, 1993). Rev Sci Instrum 64(11):33423342. https://doi.org/10.1063/1.1144449
53. Sneddon IN (1965) The relation between load and penetration in the axisymmetric boussinesq problem for a punch of arbitrary profile. Int J Eng Sci 3(1):47-57

54. Stolz M, Raiteri R, Daniels AU, VanLandingham MR, Baschong W, Aebi U (2004) Dynamic elastic modulus of porcine articular cartilage determined at two different levels of tissue organization by indentation-type atomic force microscopy. Biophys J 86(5): 3269-3283. https://doi.org/10.1016/S0006-3495(04)74375-1

55. Géradin M, Rixen DJ (2015) Mechanical vibrations - theory and applications to structural dynamics. 3 edn. John Wiley \& Sons

56. Landau LD, Lifshitz EM (1986) Theory of elasticity. Course of theoretical physics, vol 7. 3rd edn. Butterworth-Heinemann

57. Zhou D, Au FTK, Cheung YK, Lo SH (2003) Three-dimensional vibration analysis of circular and annular plates via the ChebyshevRitz method. Int J Solids Struct 40(12):3089-3105. https://doi.org/ 10.1016/S0020-7683(03)00114-8

58. Schmitz TL, Smith KS (2012) Mechanical vibrations - modeling and measurement, vol 1. Springer, New-York doi:https://doi.org/ 10.1007/978-1-4614-0460-6

59. Suzuki S, Ikada Y (2013) Sealing effects of cross-linked gelatin. J Biomater Appl 27(7):801-810. https://doi.org/10.1177/ 0885328211426491

60. Niehues E, Quadri MGN (2017) Spinnability, morphology and mechanical properties of gelatins with different bloom index. Braz J Chem Eng 34(1):253-261. https://doi.org/10.1590/0104-6632. 20170341s20150418

61. Bai ZH, Reyes JMM, Montazami R, Hashemi N (2014) On-chip development of hydrogel microfibers from round to square/ribbon shape. J Mater Chem A 2(14):4878-4884. https://doi.org/10.1039/ c3ta14573e

62. Taberlet N, Ferrand J, Camus E, Lachaud L, Plihon N (2017) How tall can gelatin towers be? An introduction to elasticity and buckling. Am J Phys 85(12):908-914. https://doi.org/10.1119/1. 5009667

63. Karimi A, Navidbakhsh M (2014) Material properties in unconfined compression of gelatin hydrogel for skin tissue engineering applications. Biomed Eng-Biomed Te 59(6):479-486. https://doi. org/10.1515/bmt-2014-0028

64. Gardel ML, Shin JH, MacKintosh FC, Mahadevan L, Matsudaira P, Weitz DA (2004) Elastic behavior of cross-linked and bundled actin networks. Science 304(5675):1301-1305. https://doi.org/10.1126/ science. 1095087

65. Hale GM, Querry MR (1973) Optical constants of water in the 200$\mathrm{nm}$ to 200- $\mu \mathrm{m}$ wavelength region. Appl Opt 12(3):555-563

66. Boedtker H, Doty P (1954) A study of gelatin molecules, aggregates and gels. J Phys Chem-Us 58(11):968-983. https://doi.org/10. 1021/j150521a010

67. Barer R, Joseph S (1954) Refractometry of Living Cells 1. Basic Principles. Q J Microsc Sci 95(4):399-423

68. Jackson JD (1962) Classical electrodynamics. John Wiley \& Sons, New York

69. Haynes WM (2016) CRC handbook of chemistry and physics. 97 edn. CRC Press

70. Rembe C, Drabenstedt A (2006) Laser-scanning confocal vibrometer microscope: theory and experiments. Rev Sci Instrum 77(8):083702. https://doi.org/10.1063/1.2336103

Publisher's Note Springer Nature remains neutral with regard to jurisdictional claims in published maps and institutional affiliations. 